\title{
Synthesis of Phosphonated Carbocyclic 2'-Oxa-3'-aza-nucleosides: Novel Inhibitors of Reverse Transcriptase
}

\author{
Ugo Chiacchio, ${ }^{*}{ }^{\dagger}$ Emanuela Balestrieri ${ }^{\ddagger}$ Beatrice Macchi ${ }^{\ddagger}$ Daniela Iannazzo, Anna Piperno, Antonio Rescifina, \\ Roberto Romeo, Monica Saglimbeni, M. Teresa Sciortino, ${ }^{\S}$ Vincenza Valveri, ${ }^{\S}$ Antonio Mastino, ${ }^{*}$, and \\ Giovanni Romeo* \\ Dipartimento Farmaco-Chimico, Università di Messina, Via SS. Annunziata, Messina 98168, Italy, Dipartimento di Scienze \\ Chimiche, Università di Catania, Viale Andrea Doria 6, Catania 95125, Italy, Dipartimento di Neuroscienze, \\ Università di Roma 'Tor Vergata', Via Montpellier 1, and IRCCS S. Lucia, Roma 00133, Italy, and Dipartimento di Scienze \\ Microbiologiche, Genetiche e Molecolari, Università di Messina, Salita Sperone 31, Messina 98168, Italy
}

Received July 28, 2004

Phosphonated carbocyclic 2'-oxa-3'-aza-nucleosides have been synthesized in good yields by 1,3-dipolar cycloaddition methodology. The cytotoxicity and the reverse transcriptase inhibitory activity of the obtained compounds have been investigated. Phosphonated carbocyclic 2'-oxa3 '-aza-nucleosides, while showing low levels of cytotoxicity, exert a specific inhibitor activity on two different reverse transcriptases, which is comparable with that of AZT, opening new perspectives on their possible use as therapeutic agents, in anti-retroviral and anti-HBV chemotherapy.

\section{Introduction}

The number of modified nucleosides has grown exponentially in recent years in response to the pressing need for new treatments against virus infections. In particular, modified nucleosides have been proved to efficiently inhibit in vitro and in vivo virus infections caused by HIV, HBV, and HTLV-1. ${ }^{1}$ Many of the nucleoside analogues proposed against the abovementioned viruses present similar mechanism of action as inhibitors of viral replication: following intracellular phosphorylation to their 5'-triphosphate forms, they serve as chain terminators, thus acting as inhibitors in the viral reverse transcription reaction. ${ }^{2}$

However, several problems associated with this kind of nucleoside analogues, due to their high toxicity and the appearance of cross-resistance, have led to the search for different structural solutions which have afforded new prodrugs comparable in their antiviral activity to the clinically used nucleoside analogues, but without their drawbacks.

The biological activity of nucleoside analogues (ddNs) showing antiviral properties is strictly linked to their conversion, through cellular enzymes, to the corresponding 5'-mono-, di, and triphosphates, which interact with viral reverse transcriptase (RT) or interfere with cell growth, slowing the cell cycle progression. In many cases, among the three successive phosphorylation steps, the first is rate-limiting, and further conversions to di- and triphosphates are catalyzed by less specific kinases. $^{3}$

The known antiviral nucleoside analogues have often shown inefficiency in the first intracellular phosphorylation step by nucleoside kinases. A possibility to

\footnotetext{
* To whom correspondence should be addressed. Phone: +39 090 356230. Fax: +39090 6766562. E-mail: gromeo@unime.it.

$\dagger$ Università di Catania.

¥ Università di Roma 'Tor Vergata'.

§ Dipartimento di Scienze Microbiologiche, Genetiche e Molecolari, Università di Messina.
}

improve the uptake of ddNs might be to bypass the phosphorylating step; unfortunately, nucleotides, due to their polar nature, are not able to cross the cell membrane efficiently. Moreover, they are readily dephosphorylated in extracellular fluids and on cell surfaces by nonspecific phosphohydrolases.

Several strategies to overcome the problem of the initial selective and regulated phosphorylation step could be foreseen. A good delivery system for a nucleoside across membranes might be represented by phosphotriester molecules, which should ensure the absorption and the transport of the active molecule and should then be able to deliver intracellular monophosphate forms. ${ }^{4}$

On this basis, recently, the use of nucleotide prodrugs (pronucleotides) incorporating enzyme-labile transient phosphate protecting groups has emerged, and a large number of prodrugs derivatives of nucleoside monophosphates have been prepared.

In this respect, an alternative approach to the discovery of new and potent RT inhibitors involves the design of phosphate analogues where the phosphate moiety is changed to isosteric and isoelectronic phosphonates. ${ }^{5}$ Those enzimatically and chemically stable phosphonate analogues, which mimic the nucleoside monophosphates, are able to overcome the instability of nucleotides toward phosphodiesterases and to enhance their cellular uptake by bypassing the initial enzymatic phosphorylation and could potentially be effective antiviral agents.

In our laboratory, we have developed the synthesis of a series of ddNs in which the furanose ring has been replaced by a $N, O$-heterocyclic ring. ${ }^{6}$ Carbocyclic 2 '-oxa$3^{\prime}$-aza-nucleosides $\mathbf{1}$ are emerging as a new important class of compounds that are interesting to synthesize in order to investigate their pharmacological activities. ${ }^{7}$ In connection with our synthetic studies on the utility of nitrones for the synthesis of interesting biologically nitrogenated compounds, ${ }^{8}$ we have devised a synthetic 


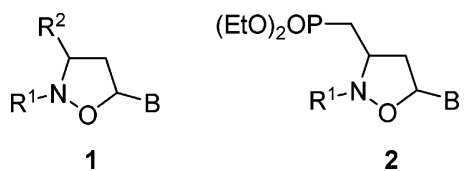

Figure 1. Carbocyclic 2'-oxa-3'-aza-nucleosides.

Scheme 1. Synthesis of Isoxazolidines 6 and 7

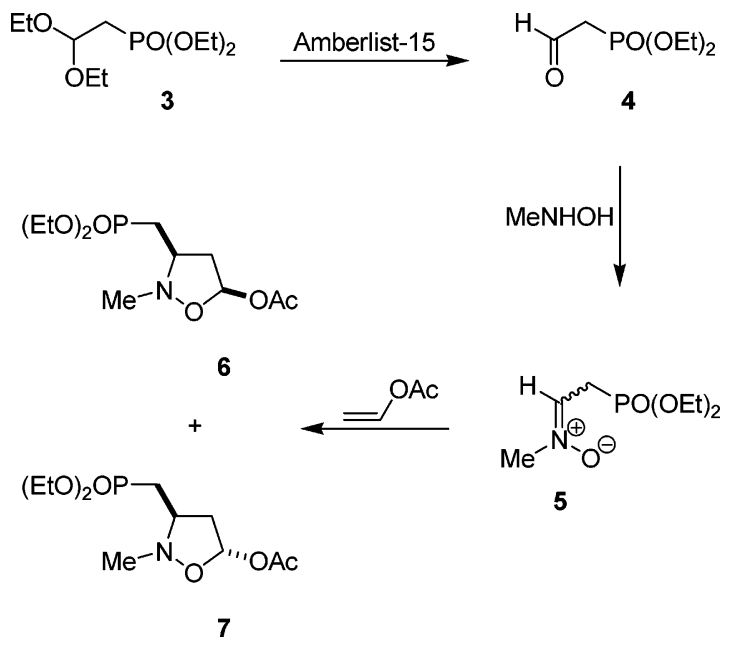

route to phoshonated carbocyclic 2'-oxa-3'-aza-nucleosides of type 2 via 1,3-dipolar cycloaddition of phosphonated nitrones (Figure 1). The compounds obtained have been proved to be potential antiviral agents: data on the biological activity show that $\mathbf{2}$ are low toxic and exert a relevant activity as $\mathrm{RT}$ inhibitors.

\section{Results and Discussion}

The strategy of the synthetic approach is based on the construction of the phosphonated nitrone $\mathbf{5}$, which has been prepared from the commercially available diethylphosphonoacetaldehyde diethyl acetal (3). Compound $\mathbf{3}$ has been efficiently hydrolyzed to the corresponding carbonyl derivative 4 by treatment with Amberlist- $15^{9}$ in acetone at room temperature: the subsequent reaction with $N$-methylhydroxylamine afforded nitrone 5 in good yield (95\%) (Scheme 1).

The cycloaddition with vinyl acetate leads to a mixture of epimeric isoxazolidines 6 and 7 (90\% overall yield) in a relative ratio $2.6: 1$. The crude mixture was purified by radial chromatography, and two cycloadducts were obtained in pure form. Their structure was confirmed by ${ }^{1} \mathrm{H}$ NMR experiments; thus, 6, the cis isomer, shows the $\mathrm{H}_{5}$ proton as doublet of doublets at $\delta$ 6.28 , while $\mathrm{H}_{3}$ proton resonates as a multiplet at $\delta 2.85$. In compound $\mathbf{7}$, the same protons give resonances at $\delta$ 6.31 (as a doublet) and 3.35 (as a multiplet).

Stereochemical assignments have been performed by NOE measurements. Thus, in compound $\mathbf{6}$ irradiation of the $\mathrm{H}_{5}$ resonance induces a positive NOE effect on $\mathrm{H}_{3}$ proton and on the downfield resonance of methylene protons at $\mathrm{C}_{4}$, indicating a cis relationship between these protons. On the contrary, irradiation of the same resonance in compound 7 resulted in the enhancement of the upfield resonance of the methylene protons at $\mathrm{C}_{4}$ (Figure 2).

The stereochemical outcome of the cycloaddition process can be explained by considering that nitrone $\mathbf{5}$ exists as a mixture of $E / Z$ isomers: NOE data indicated
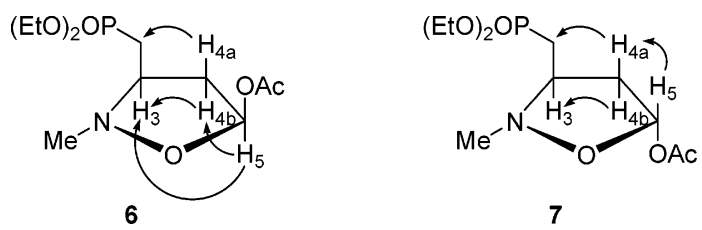

Figure 2. Relevant NOE effects on compounds 6 and 7.

Table 1. AM1 Calculations Results on Transition State Structures for Isoxazolidines $\mathbf{6}$ and $\mathbf{7}$

\begin{tabular}{lccc}
\hline \multirow{2}{*}{ transition state } & \multirow{2}{*}{$\Delta H_{\mathrm{f}}$} & \multicolumn{2}{c}{ percent } \\
\cline { 3 - 4 }$(\mathrm{kcal} / \mathrm{mol})$ & calcd & obsd \\
\hline$(E)$-exo (trans adduct 7) & -228.297 & 31.18 & 28.57 \\
$(E)$-endo (cis adduct 6) & -228.752 & 66.87 & 71.43 \\
$(Z)$-exo (cis adduct 6) & -226.289 & 1.07 & \\
$(Z)$-endo (trans adduct 7) & -226.167 & 0.88 & \\
\hline
\end{tabular}

Scheme 2. Synthesis of Phosphonated Carbocyclic 2'-Oxa-3'-aza-nucleosides 11 and 12

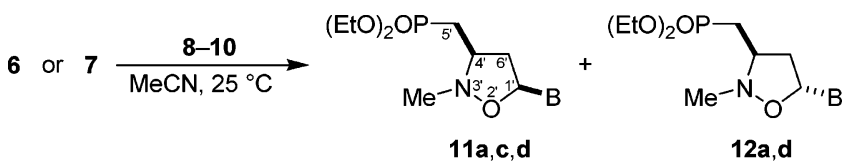

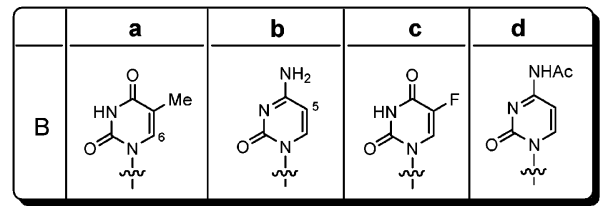

that the $Z$ form is predominant $(Z / E$ ratio $=5: 1)$. Thus, the major product 6 could be formed by the $(Z)$-nitrone reacting in an exo mode or by the $(E)$-nitrone reacting in an endo mode, in agreement with the results reported for similar $\alpha$-alkoxynitrones. ${ }^{10} \mathrm{AM} 1$ calculations ${ }^{11}$ give theoretical support to the experimental data, indicating that the $(E)$-isomer as the more reactive form of nitrone 5: the $(E)$-endo transition state leading to $\mathbf{6}$ is about $0.45 \mathrm{kcal} / \mathrm{mol}$ more stable than the $(E)$-exo one leading to trans stereoisomer 7. These values agree satisfactorily with the observed 2.5:1 cis/trans ratio (Table 1 ).

Two cycloadducts were independently coupled with silylated nucleobases, according to the Vorbrüeggen methodology. ${ }^{12}$ The condensation with silylated thymine (8), $N$-acetylcytosine (9), and 5-fluorouracil (10), performed in acetonitrile at $55{ }^{\circ} \mathrm{C}$ in the presence of 0.4 equiv of TMSOTf as catalyst, proceeded with good yields: a mixture of $\beta$ - and $\alpha$-nucleosides 11 and 12 has been obtained (Scheme 2). The compounds 11d and 12d were further treated with $5.0 \%$ aqueous sodium carbonate to give the deacetylated derivatives $\mathbf{1 1 b}$ and $\mathbf{1 2 b}$.

Pure anomers were isolated by flash chromatography, and the relative configuration was assigned on the basis of ${ }^{1} \mathrm{H}$ NMR and NOE experiments. In particular, for $\beta$-compounds 11, irradiation of $\mathrm{H}_{1}$ increased the resonance of $\mathrm{H}_{6}, \mathrm{H}_{4^{\prime}}$, and $\mathrm{H}_{6^{\prime}} \mathrm{b}$ (the downfield resonance of methylene protons at $\mathrm{C}_{6^{\prime}}$ ). Conversely, when $\mathrm{H}_{6^{\prime} \mathrm{b}}$ was irradiated, enhancements of the $\mathrm{H}_{1^{\prime}}, \mathrm{H}_{4^{\prime}}$, and $\mathrm{H}_{6^{\prime}}$ a signals were observed, while irradiation of $\mathrm{H}_{6}$ a gives rise to a positive NOE effect for $\mathrm{H}_{6}$ and $\mathrm{H}_{6}$ b. These data unambiguously indicate a $\beta$-configuration where $\mathrm{H}_{4^{\prime}}$ and the pyrimidine base are in a trans relationship.

Furthermore, the $\alpha$-configuration for anomers 12 was supported by the strong NOE effect observed for $\mathrm{H}_{6}$ when irradiating $\mathrm{H}_{4}$. 
Table 2. Evaluation of Cytotoxicity of Phosphonates in Lymphoid and Monocytoid Cell Lines ${ }^{a}$

\begin{tabular}{|c|c|c|c|c|c|c|c|c|c|}
\hline \multirow[b]{2}{*}{ cell line } & \multicolumn{3}{|c|}{$24 \mathrm{~h}$} & \multicolumn{3}{|c|}{$48 \mathrm{~h}$} & \multicolumn{3}{|c|}{$72 \mathrm{~h}$} \\
\hline & AdT-P & AdC-P & AdF-P & AdT-P & AdC-P & AdF-P & AdT-P & AdC-P & AdF-P \\
\hline Molt-3 & $>1000$ & $>1000$ & $247 \pm 37$ & $>1000$ & $>1000$ & $197^{b}$ & $>1000$ & $>1000$ & $141 \pm 25$ \\
\hline U937 & $>1000$ & $>1000$ & $\mathrm{ND}^{c}$ & $>1000$ & $>1000$ & $\mathrm{ND}^{c}$ & $>1000$ & $>1000$ & $\mathrm{ND}^{c}$ \\
\hline HL-60 & $>1000$ & $>1000$ & $>1000$ & $>1000$ & $>1000$ & $457 \pm 53$ & $>1000$ & $>1000$ & $408^{b}$ \\
\hline
\end{tabular}

${ }^{a}$ Cells were exposed under optimal culture conditions to concentrations of AdT-phosphonate (AdT-P, 11a), AdC-phosphonate (AdC-P, 11b), and AdF-phosphonate (AdF-P, 11c), ranging from 16 to $1000 \mu \mathrm{M}$, or control medium for the times indicated. Values indicate the $\mathrm{CC}_{50}$, calculated as the concentrations of the drug required to cause $50 \%$ toxicity, detected by trypan blue exclusion test. Each value is determined by three or more experiments. ${ }^{b}$ Mean of two values. ${ }^{c}$ Not done.

Table 3. Evaluation of Apoptosis Induced by Phosphonates in Lymphoid and Monocytoid Cell Lines ${ }^{a}$

\begin{tabular}{|c|c|c|c|c|c|c|c|c|c|}
\hline \multirow[b]{2}{*}{ cell line } & \multicolumn{3}{|c|}{$24 \mathrm{~h}$} & \multicolumn{3}{|c|}{$48 \mathrm{~h}$} & \multicolumn{3}{|c|}{$72 \mathrm{~h}$} \\
\hline & $\overline{\text { AdT-P }}$ & AdC-P & AdF-P & $\overline{\text { AdT-P }}$ & AdC-P & AdF-P & $\overline{\text { AdT-P }}$ & AdC-P & AdF-P \\
\hline Molt-3 & $>1000$ & $>1000$ & $457 \pm 31$ & $>1000$ & $>1000$ & $277^{b}$ & $>1000$ & $>1000$ & $170 \pm 30$ \\
\hline U937 & $>1000$ & $>1000$ & $\mathrm{ND}^{c}$ & $>1000$ & $>1000$ & $\mathrm{ND}^{c}$ & $>1000$ & $>1000$ & $\mathrm{ND}^{c}$ \\
\hline HL-60 & $>1000$ & $>1000$ & $250 \pm 32$ & $>1000$ & $>1000$ & $151 \pm 22$ & $>1000$ & $>1000$ & $\mathrm{ND}^{c}$ \\
\hline
\end{tabular}

${ }^{a}$ Cells were exposed under optimal culture conditions to concentrations of AdT-phosphonate (AdT-P, 11a), AdC-phosphonate (AdC-P, 11b) and AdF-phosphonate (AdF-P, 11c), ranging from 16 to $1000 \mu \mathrm{M}$, or control medium for the times indicated. Values indicate the $\mathrm{AC}_{50}$, calculated as the concentrations of the drug required to cause 50\% apoptosis, detected by microscopy analysis following staining with acridine orange. Each value is determined by three or more experiments. ${ }^{b}$ Mean of two values. ${ }^{c}$ Not done.

The ratio between $\alpha$ - and $\beta$-nucleosides does not change when the nucleosidation reaction was performed starting from the crude mixture of isoxazolidines without any preventive separation. These results show that the coupling reaction of isoxazolidines with silylated bases occurs without selectivity with respect to the anomeric center. As previously reported, this is due to the formation of an intermediate oxonium ion, which would not be expected to have any significant facial bias, since the substituents at $\mathrm{C}_{3}$ and $\mathrm{C}_{4}$ are not in close proximity to induce any steric effect upon the incoming group at $\mathrm{C}_{5} .{ }^{13}$

The anomeric distribution obtained depends on the attacking nucleobase. With 5-fluorouracil (10), the $\beta$-anomers clearly predominate as nearly exclusive products, while, in the case of thymine (8) and $\mathrm{N}$ acetylcytosine $(\mathbf{9})$, a significant amount of the $\alpha$-nucleoside has been obtained. Evidently, the attack on the intermediate oxonium ion from either the $\alpha$ - or $\beta$-side is possible, ${ }^{14}$ and hence the product distribution is sensitive to structural changes of the reactants.

Biological Tests. Cytotoxicity Assays. One of the major limitations in the use of antiviral drugs is their toxicity to uninfected cells. For this reason, we tested the cytotoxicity of the newly synthesized compounds using a conventional viability assay, such as the trypan blue exclusion test, in cell lines of lymphoid and monocytoid origin. Moreover, considering the pivotal role of apoptosis as a mechanism, triggered by cellular signals as well as by a variety of drugs, for the controlled removal of dead cells, particularly of the immune system, we assayed the ability of the new compounds to specifically induce apoptosis in the same cell lines. Apoptosis was detected by morphological analysis, following staining with a DNA-binding dye, using microscopy. Results, expressed as $\mathrm{CC}_{50}$ (cytotoxic concentration 50 , the concentration that causes $50 \%$ toxicity by trypan blue) and $\mathrm{AC}_{50}$ (apoptotic concentration 50, the concentration required to cause apoptosis in $50 \%$ of treated cells), are reported in Tables 2 and 3, respectively.

No significant toxicity, when using both the classical trypan blue test and the apoptosis assay, was detected in 3 days of treatment in the lymphoid (Molt-3) and monocytoid (U937, HL-60) cell lines assayed, following treatment with AdC-P (11b) or AdT-P (11a). Conversely, AdF-P (11c) was shown to cause detectable levels of toxicity using both the assays. In particular, the monocytoid HL-60 cell line was more sensitive to apoptosis induced by AdF-P rather than the lymphoid cells. Nevertheless, $\mathrm{CC}_{50}$ and $\mathrm{AC}_{50}$ calculated for AdF-P were relatively high, showing that all the phosphonate compounds tested were of low toxicity or nontoxic.

Inhibition of Reverse Transcriptase Activity in Vitro. The ability of the newly synthesized compounds to inhibit retroviral RNA-dependent DNA polymerase (reverse transcriptase) activity was determined by means of a novel, cell-free assay, originally developed by us for a preliminary screening of potential inhibitors of reverse transcriptase (RT). In this assay, which is described here for the first time, RNA isolated from stable transfectants expressing constitutively the glycoprotein D (gD) of HSV-1 was used as a template for the RT activity of commercial avian myeloblastosis virus RT (AMV-RT) and moloney murine leukemia virus RT (MLV-RT). These two RTs were chosen on the basis of their well-known characteristic of being extensively utilized commercial sources for routine RT-PCR, with high activity. The RT activity was revealed by directly detecting specific HSV-1-gD DNA following a successive polymerase chain reaction (PCR) amplification using specific primers. Zidovudine (AZT), a well-known nucleoside RT inhibitor, and (5'S)-5-fluoro-1-isoxazolidin5 -yl- $1 H$-pyrimidine-2,4-dione (ADF), a nucleoside compound showing biological activity ${ }^{6}$ but lacking RTinhibitory activity in preliminary tests, as expected by the absence of a hydroxymethyl group in the furanose ring, were utilized in the assay as internal positive and negative controls, respectively. Before being assayed, the new compounds and AZT were incubated with a crude extract from human peripheral blood mononuclear cells (PBMCs) stimulated with PHA for $72 \mathrm{~h}$. Preincubation with the PBMC crude extract served to supply the necessary enzymes to transform the prodrugs from esters to mono-, di-, and triphosphate or phosphonate forms for effective inhibition of RT activity and cDNA elongation. Results obtained using AMV-RT are shown 

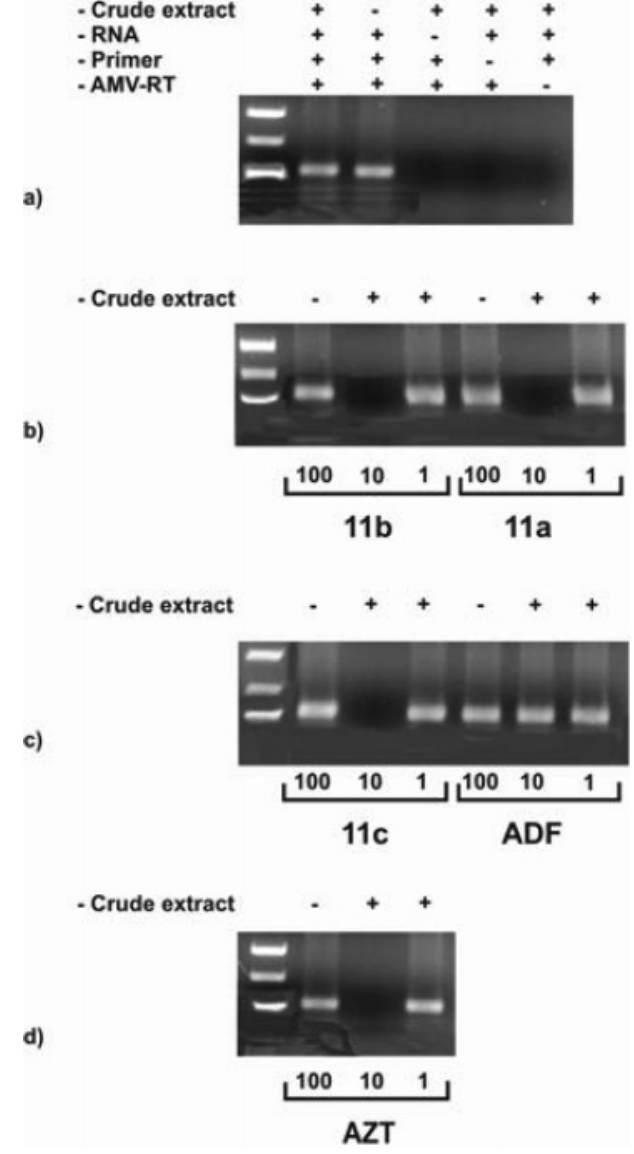

Figure 3. Inhibition of reverse transcriptase (RT) activity of compounds 11a-c, in comparison with $\mathrm{ADF}$ (negative control) and AZT (reference control), evaluated by a cell-free assay based on a RT-PCR reaction. RNA template from glycoprotein $\mathrm{D}$ of HSV-1 was reversely transcribed by AMV-RT into cDNA in the presence of the compounds. DNA was then amplified and visualized on ethidium bromide containing agarose gel. (a) Control runs in which RT activity was assayed, in the absence of the nucleoside compounds, with or without the addition of a crude extract from stimulated PBMCs and with single subtraction, from the reaction mixture, of isolated RNA, primers, or AMV-RT. (b) Experimental runs in which RT activity was assayed in the presence of AdC-P or AdT-P at the concentrations of 100,10 , or $1 \mathrm{nM}$, with or without preincubation with the crude extract. (c) Experimental runs in which RT activity was assayed in the presence of AdF-P or $\mathrm{ADF}$ at the concentrations of 100,10 , or $1 \mathrm{nM}$, with or without preincubation with the crude extract. (d) Experimental runs in which RT activity was assayed in the presence of AZT at the concentrations of 100,10 , or $1 \mathrm{nM}$, with or without preincubation with the crude extract.

in Figure 3. The quality and the specificity of the assay are illustrated in Figure 3a, where RT activity was assayed in the absence of the nucleoside compounds. No difference was observed with or without the addition of the crude extract to the complete reaction mixture in the appearance of a clear band of amplified DNA. No amplification product was detected when isolated RNA, primers, or AMV-RT was singly subtracted from the reaction mixture. No inhibitory effect was exerted by AdC-P, AdT-P, or AdF-P at $100 \mathrm{nM}$ concentration, as well as at lower concentrations (not shown), in the absence of crude extract activation (Figure 3b,c). Conversely, following exposure of the nucleosides to the crude extract from (PBMCs), all phosphonates completely inhibited the formation of amplified products at
$10 \mathrm{nM}$ concentration, with the exception of ADF, which was completely inactive. The same results were obtained when a concentration of $100 \mathrm{nM}$ was used (not shown). No RT-inhibitory activity was observed for all the compounds at $1 \mathrm{nM}$ concentration. As shown in Figure $3 \mathrm{~d}$, the activity of AZT overlapped with that of phosphonates. Similar results were obtained when MLV-RT was utilized. These results demonstrate that the phosphonate compounds exert a specific inhibitory action on $\mathrm{RT}$ from at least two different retroviruses, which is comparable with that of AZT.

\section{Conclusions}

Phosphonated $N, O$-nucleosides, containing thymine, fluorouracil, and cytosine, have been synthesized in good yields by 1,3-dipolar cycloaddition methodology.

The cytotoxicity and the RT-inhibitory activity of the obtained compounds have been investigated. The results indicate that the synthesized phosphonate nucleosides presented low levels of cytotoxicity assessed by a conventional assay to detect viability, such as the trypan blue exclusion test, as well as by detection of cell death by apoptosis. More importantly, the obtained phosphonate nucleosides seem to act as RT inhibitors, when tested in a simple cell-free assay, as powerfully as AZT is, opening new perspectives in future investigations on their possible use as therapeutic agents, particularly in antiretroviral and anti-HBV chemotherapy.

\section{Experimental Section}

General. Melting points were determined with a Kofler apparatus and are uncorrected. Elemental analyses were performed with a Perkin-Elmer elemental analyzer. NMR spectra were recorded on a Varian instrument at $500 \mathrm{MHz}$ $\left({ }^{1} \mathrm{H}\right)$ and at $125 \mathrm{MHz}\left({ }^{13} \mathrm{C}\right)$ using deuteriochloroform or deuterated methanol as solvent; chemical shifts are given in ppm from TMS as internal standard. NOE experiments were performed by a modified cyclenoe sequence, implemented in Darmstadt, which does alternate scan subtraction of two FIDs in which the saturation frequency is moved on-resonance and off-resonance. Power may be reduced from ordinary NOE experiments because the irradiation is cycled through the lines of the multiplet; it is a steady-state NOE in which a single resonance is saturated at low power for approximately $5 \times$ $\mathrm{T} 1$ (5 s in our case) before acquiring the FID. Thin-layer chromatographic separations were performed on Merck silica gel $60-\mathrm{F}_{254}$ precoated aluminum plates. Preparative separations were carried out by flash chromatography using Merck silica gel $0.035-0.070 \mathrm{~mm}$. Preparative centrifugally accelerated radial thin-layer chromatography (PCAR-TLC) was performed with a Chromatotron Model $7924 \mathrm{~T}$ (Harrison Research, Palo Alto, CA); the rotors (1 or $2 \mathrm{~mm}$ layer thickness) were coated with silica gel Merck grade type 7749, TLC grade, with binder and fluorescence indicator (Aldrich 34,644-6) and the eluting solvents were delivered by the pump at a flow rate of $0.5-1.5 \mathrm{~mL} / \mathrm{min}$.

The identification of samples from different experiments was secured by mixed melting point and superimposable NMR spectra.

Starting Materials. Diethylphosphonoacetaldehyde diethyl acetal (3), thymine (8), $N$-acetylcytosine $(\mathbf{9})$, and 5 -fluorouracil (10) were purchased from Aldrich Co. All solvents were dried according to literature methods.

Diethyl (2E)- and (2Z)-2-[Methyl(oxido)imino]ethylphosphonate (5). A solution of diethyl 2-oxoethylphosphonate $^{9}$ (4) $(20 \mathrm{mmol}), N$-methylhydroxylamine hydrochloride (20 $\mathrm{mmol})$, and triethylamine $(20 \mathrm{mmol})$ in toluene $(70 \mathrm{~mL})$ was stirred, at room temperature, for $3 \mathrm{~h}$. The reaction mixture was filtered, the solvent was evaporated under reduced pressure, and the residue was purified by silica gel flash chroma- 
tography $\left(\mathrm{CHCl}_{3} / \mathrm{CH}_{3} \mathrm{OH}\right.$ 95:5) to give nitrone 5 as colorless oil. Yield $95 \%(Z / E=5 / 1)$.

Synthesis of Isoxazolidines 6 and 7. A solution of nitrone $5(5.7 \mathrm{mmol})$ in vinyl acetate $(30 \mathrm{~mL})$ was stirred at $60{ }^{\circ} \mathrm{C}$ for $24 \mathrm{~h}$. After this period, the reaction mixture was evaporated under reduced pressure and the residue purified by radial chromatography $\left(\mathrm{CHCl}_{3} / \mathrm{CH}_{3} \mathrm{OH}\right.$ 99.5:0.5; spot evidenced with cerium molibdic reagent) to give the pure isoxazolidines 6 and 7.

(3RS,5SR)-3-[(Diethoxyphosphoryl)methyl]-2-methylisoxazolidin-5-yl acetate (6): yield 65\%, light yellow oil.

(3RS,5RS)-3-[(Diethoxyphosphoryl)methyl]-2-methylisoxazolidin-5-yl acetate (7): yield 25\%, light yellow oil.

General Procedure for the Preparation of Nucleosides 11 and 12. A suspension of bases 8-10 $(0.62 \mathrm{mmol})$ in dry acetonitrile $(3 \mathrm{~mL})$ was treated with bis(trimethylsilyl)acetamide (BSA) $(2.54 \mathrm{mmol})$ and refluxed for 15 min under stirring. To the clear solution obtained were added a solution of the epimeric isoxazolidines $\mathbf{6} / \mathbf{7}(0.52 \mathrm{mmol})$ in dry acetonitrile $(3 \mathrm{~mL})$ and trimethylsilyltriflate (TMSOTf) $(0.4 \mathrm{mmol})$ dropwise, and the reaction mixture was stirred at $55^{\circ} \mathrm{C}$ for 6 h. After being cooled at $0{ }^{\circ} \mathrm{C}$, the solution was neutralized by careful addition of aqueous $5 \%$ sodium bicarbonate and then concentrated in vacuo. After the addition of dichloromethane $(8 \mathrm{~mL})$, the organic phase was separated, washed with water $(2 \times 10 \mathrm{~mL})$, dried over sodium sulfate, filtered, and evaporated to dryness. The residue was purified by flash chromatography $\left(\mathrm{CHCl}_{3} / \mathrm{MeOH}\right.$ 95:5) to give $\beta$-nucleosides 11a,c,d and $\alpha$-nucleosides 12a,d.

Diethyl \{(1'SR,4'RS $)-1^{\prime}$-[[(5-methyl-2,4-dioxo-3,4-dihydropyrimidin-1(2H)-yl)]-3'-methyl-2' -oxa-3'-azacyclopent$4^{\prime}$-yl]\}methylphosphonate (11a): yield 68\%, sticky oil.

Diethyl $\left\{\left(1^{\prime} R S, 4^{\prime} R S\right)-1^{\prime}-[[(5-m e t h y l-2,4-d i o x o-3,4-d i h y-\right.$ dropyrimidin-1 $(2 H)$-yl)]-3'-methyl-2'-oxa-3'-azacyclopent$\mathbf{4}^{\prime}$-yl]\}methylphosphonate (12a): yield $12 \%$, sticky oil.

Diethyl $\left\{\left(1^{\prime} S R, 4^{\prime} R S\right)-1^{\prime}\right.$-[4-(acetylamino)-2-oxopyrimidin-1(2H)-yl]-3'-methyl-2'-oxa-3'-azacyclopent-4'-yl methylphosphonate (11d): yield 56\%, sticky oil.

Diethyl $\left\{\left(1^{\prime} R S, 4^{\prime} R S\right)-1^{\prime}\right.$-[4-(acetylamino)-2-oxopyrimidin-1(2H)-yl]-3'-methyl-2' -oxa-3'-azacyclopent-4' -yl $\}$ methylphosphonate (12d): yield 14\%, sticky oil.

Diethyl [(1'SR,4'RS)-1'-(5-fluoro-2,4-dioxo-3,4-dihydropyrimidin-1(2H)-yl)-3'-methyl-2'-oxa-3'-azacyclopent-4'yl]methylphosphonate (11c): yield 75\%, sticky oil

Synthesis of Diethyl [(1'SR,4'RS)-1'-(4-amino-2-oxopyrimidin-1 (2H)-yl)-3' -methyl-2' -oxa-3' -azacyclopent-4' -yl]methylphosphonate (11b). A solution of 11d (100 mg) in a mixture of aqueous $\mathrm{K}_{2} \mathrm{CO}_{3}(5 \%, 5 \mathrm{~mL})$ and methanol $(5 \mathrm{~mL})$ was left to stir for $4 \mathrm{~h}$; solvent was then evaporated under reduced pressure, and the residue was purified by flash chromatography $\left(\mathrm{CHCl}_{3} / \mathrm{CH}_{3} \mathrm{OH}\right.$ 95:5) to give the deacetylated compound 11b: yield 90\%, colorless sticky oil.

Evaluation of Toxicity and Apoptosis. Toxicity was evaluated by a standard viability assay, using the trypan blue exclusion test. Apoptosis was evaluated by morphological analysis of the cells, performed following staining with acridine orange as previously described. ${ }^{15}$ Briefly, over 600 cells, including those showing typical apoptotic characteristics, were counted using a fluorescence microscope. The identification of apoptotic cells was based on the presence of uniformly stained nuclei showing chromatin condensation and nuclear fragmentation.

Reverse Transcriptase Inhibition Assay. The capacity of the described compounds to inhibit RT activity was investigated by evaluating their activity toward cDNA generation from an RNA template using a cell-free RT reaction assay, based on routinely adopted RT-PCR procedures. This included RNA from stable transfectants expressing gD of HSV-1, as a template. The gD-expressing transfectants have been described elsewhere. ${ }^{16}$ Transfectants were grown in D-MEM plus $12 \%$ fetal bovine serum (FBS), $400 \mu \mathrm{g} / \mathrm{mL}$ G418 (GibcoInvitrogen Co., Paisley, Scotland, UK), and $30 \mu \mathrm{g} / \mathrm{mL}$ BrdU (Sigma-Aldrich Co., St. Louis, MO). The choice of a nonretroviral, ectopic cellular system of expression as a source of RNA template was motivated to avoid problems with retroviral or human DNA, possibly present in reagents utilized during the execution of the entire assay. Cells underwent passage every 2 days and at each passage cell growth was monitored by evaluating living cells, using the trypan blue dye exclusion test. The new synthesized compounds and the nucleosides AdFU $^{6}$ or AZT (Sigma-Aldrich Co.) were activated in vitro through incubation with a crude extract from $1 \times 10^{6}$ PBMCs, which served as enzyme supplier for phosphorylation processes. PBMCs, separated by density gradient from peripheral blood of healthy donors, negative for HIV-1/2, HTLV-1/2, and $\mathrm{B} / \mathrm{C}$ hepatitis, were previously stimulated with PHA $(2 \mu \mathrm{g} / \mathrm{mL})$ and IL-2 $(20 \mathrm{U} / \mathrm{mL})$, for $72 \mathrm{~h}$ in RPMI plus $20 \% \mathrm{FBS}$. For the preparation of the crude extract, PBMCs were rinsed three times in cold PBS and then solubilized in lysis buffer $(50 \mathrm{mM}$ Tris-HCl $\mathrm{pH} 7.4,1 \mathrm{mM}$ EDTA, $1 \mathrm{mM}$ EGTA $\mathrm{pH} 7.4,0.05 \%$ Triton-X, NaCl $150 \mathrm{mM}, 0.25 \%$ sodium deoxycholate, $0.1 \% \mathrm{NP}$ 40, and, freshly added, $1 \mathrm{mM}$ PMSF, $15 \mu \mathrm{M}$ DTT, $5 \mu \mathrm{g} / \mathrm{mL}$ leupeptin, $5 \mu \mathrm{g} / \mathrm{mL}$ pepstatin, $5 \mu \mathrm{g} / \mathrm{mL}$ aprotinin, $1 \mathrm{mM} \mathrm{Na}{ }_{3-}$ $\mathrm{VO}_{4}, 20 \mathrm{mM} \mathrm{Na} 3 \mathrm{~F}$, all from Sigma) on ice and centrifuged at $10000 \mathrm{rpm}$. The compounds were incubated with the crude extract from stimulated PBMCs, for $1 \mathrm{~h}$ on ice. The crude extract was then inactivated for $5 \mathrm{~min}$ at $95^{\circ} \mathrm{C}$. RNA isolation from $5 \times 10^{6} \mathrm{gD}$-expressing transfectants was performed using Trizol (Gibco-Invitrogen Co.), according to the manufacturer's instructions. Total RNA ( $1 \mu \mathrm{g})$ was reverse transcribed using a reverse primer (5'-TGT CGT CAT AGT GGG CCT CCA T-3') $(0.5 \mu \mathrm{M})$ specific for a sequence of the HSV-1 US6 gene that codes for $\mathrm{gD}$, in a reaction mix containing $\mathrm{RT}$ buffer $(1 \times)$, RNase inhibitor (100 U), dNTP (4 mM), DTT (10 mM), and 30 $\mathrm{U}$ of avian myeloblastosis virus RT (AMV-RT) or $40 \mathrm{U}$ of moloney murine leukemia virus RT (MLV-RT) (all from Promega Co., Madison WI). The reactions were performed in the presence or in the absence of the activated compounds, at the concentration of 100,10 , and $1 \mathrm{nM}$, for $1 \mathrm{~h}$ at $37^{\circ} \mathrm{C}$. After incubation at $95{ }^{\circ} \mathrm{C}$ for $5 \mathrm{~min}, 5 \mu \mathrm{L}$ of the $\mathrm{RT}$ reaction product was used for DNA PCR in a reaction mix containing $1 \times$ Taq Gold buffer (Promega Co.), $0.5 \mu \mathrm{M}$ primers (US6 reverse 5'TGT CGT CAT AGT GGG CCT CCA T-3' and US6 forward 5'AGA CTT GTT GTA GGA GCA TTC G-3'), $0.3 \mathrm{mM}$ dNTP, $5 \mathrm{mM} \mathrm{MgCl}_{2}$, and $1.25 \mathrm{U}$ Taq Gold (Promega Co.), for 30 cycles $\left(30 \mathrm{~s}\right.$ at $95{ }^{\circ} \mathrm{C}, 30 \mathrm{~s}$ at $60{ }^{\circ} \mathrm{C}$, and $45 \mathrm{~s}$ at $72^{\circ} \mathrm{C}$ ) on a Cetus DNA thermal cycler 2400 (Perkin-Elmer, Norwalk, CT). Following the final cycle, samples were incubated at $72{ }^{\circ} \mathrm{C}$ for 20 min to ensure the completion of the final extension step. Amplified DNA (350 bp) was visualized on 1\% agarose gel containing $10 \mu \mathrm{g} / \mathrm{mL}$ ethidium bromide in $1 \times \mathrm{TAE}$ buffer.

Acknowledgment. This work was partially supported by M.I.U.R. (progetto P.R.I.N. 2002 and F.I.R.B.). The C.I.N.M.P.I.S. (Italy) is also acknowledged for a fellowship to M.S.

Supporting Information Available: Spectroscopic data $\left({ }^{1} \mathrm{H}\right.$ and ${ }^{13} \mathrm{C}$ NMR) and elemental analyses data of compounds $\mathbf{5}-\mathbf{7}, \mathbf{1 1 a}-\mathbf{d}, \mathbf{1 2 a}$, and $\mathbf{1 2 d}$. This material is available free of charge via the Internet at http://pubs.acs.org.

\section{References}

(1) (a) Richman, D. D. HIV Chemoterapy. Nature 2001, 410, 9951001. (b) De Clerca, E. New Developments in Anti-HIV Chemotherapy. Biochim. Biophys. Acta 2002, 1587, 258-275. (c) De Clerca, E. New Anti-HIV Agents and Targets. Med. Res. Rev. 2002, 22, 531-565. (d) Macchi, B.; Balestrieri, E.; Mastino, A Effects of Nucleoside-Based Anti-Retroviral Chemotherapy on Human T-Cell Leukaemia/Lymphotropic Virus Type-1 (HTLV1). J. Antimicrob. Chemother. 2003, 51, 1327-1330. (e) De Clercq, E. Antiviral Drugs in Current Clinical Use. J. Clin. Virol. 2004, 30, 115-133.

(2) (a) Mitsuya, H.; Yarchoan, R.; Broder, S. Molecular Targets for Aids Therapy. Science 1990, 249, 1533-1544. (b) De Clercq, E. HIV Resistance to Reverse Transcriptase Inhibitors. Biochem. Pharmacol. 1994, 47, 155-169. (c) Katz, R. A.; Skalka, A. M The Retroviral Enzymes. Annu. Rev. Biochem. 1994, 63, 133173. (d) Turner, B. G.; Summers, M. F. Structural Biology of HIV. J. Mol. Biol. 1999, 285, 1-32. (e) Jonckheere, H.; Anne, J.; De Clercq, E. The HIV-1 Reverse Transcription (RT) Process as Target for RT Inhibitors. Med. Res. Rev. 2000, 20, 129-154. 
(3) Perigaud C.; Girardet J. L.; Gosselin G.; Imbach J. L. Comments on Nucleotide Delivery Forms. In Advances in Antiviral Drug Design; De Clercq, E., Ed., 1995; Vol. 2, pp 167-172.

(4) Vallette, G.; Pompon, A.; Girardet, J.-L.; Cappellacci, L.; Fianchetti, P.; Grifantini, M.; La Colla, P.; Loi, A. G.; Perigaud, C.; Gosselin, G.; Imbach, J.-L. Decomposition Pathways and in Vitro HIV Inhibitors Effect of IsoddA Pronucleotides: Toward a Rational Approach for Intracelluar Delivery of Nucleosides 5' Monophosphates. J. Med. Chem. 1996, 39, 1981-1990.

(5) Mulato, A. S.; Cherrington, J. M. Anti-HIV Activity of Adefovir PMEA and PMPA in Combination with Antiretroviral Compounds: In Vitro Analyses. Antiviral Res. 1997, 36, 91-97.

(6) Chiacchio, U.; Corsaro, A.; Iannazzo, D.; Piperno, A.; Pistarà V.; Rescifina, A.; Romeo, R.; Valveri, V.; Mastino, A.; Romeo, G. Enantioselective Syntheses and Cytotoxicity of $N, O$-Nucleosides. J. Med. Chem. 2003, 46, 3696-3702.

(7) (a) Chiacchio, U.; Corsaro, A.; Iannazzo, D.; Piperno, A.; Pistarà V.; Rescifina, A.; Romeo, R.; Sindona, G.; Romeo, G. Diastereoand Enantioselective Synthesis of $N, O$-Nucleosides. Tetrahedron: Asymmetry 2003, 14, 2717-2723. (b) Chiacchio, U.; Borrello, L.; Iannazzo, D.; Merino, P.; Piperno, A.; Rescifina, A.; Richichi, B.; Romeo, G. Enantioselective Synthesis of $N, O$ Psiconucleosides. Tetrahedron: Asymmetry 2003, 14, 24192425.

(8) (a) Chiacchio, U.; Corsaro, A.; Gumina, G.; Rescifina, A.; Iannazzo, D.; Piperno, A.; Romeo, G.; Romeo, R. Homochiral $\alpha$-Dand $\beta$-D-Isoxazolidinylthymidines Via 1,3-Dipolar Cycloaddition. J. Org. Chem. 1999, 64, 9321-9327. (b) Chiacchio, U.; Corsaro, A.; Iannazzo, D.; Piperno, A.; Procopio, A.; Rescifina, A.; Romeo, G.; Romeo, R. A Stereoselective Approach to Isoxazolidinyl Nucleosides. Eur. J. Org. Chem. 2001, 1893-1898. (c) Chiacchio, U.; Corsaro, A.; Iannazzo, D.; Piperno, A.; Rescifina, A.; Romeo, R.; Romeo, G. Diastereoselective Synthesis of N,O-Psiconucleosides via 1,3-Dipolar Cycloadditions. Tetrahedron Lett. 2001, 42, 1777-1780. (d) Iannazzo, D.; Piperno, A.; Pistarà, V.; Rescifina,
A.; Romeo, R. Modified Nucleosides. A General and Diastereoselective Approach to N,O-Psiconucleosides. Tetrahedron 2002 $58,581-587$

(9) Coppola, G. M. Amberlyst-15, a Superior acid Catalyst for the Cleavage of Acetals. Synthesis 1984, 1021-1023.

(10) Merino, P.; Revuelta, J.; Tejero, T.; Chiacchio, U.; Rescifina A. Romeo, G. A DFT Study on the 1,3-Dipolar Cycloaddition Reactions of $C$-Methoxycarbonyl- $N$-methyl Nitrone with Methyl Acrylate and Vinyl Acetate. Tetrahedron 2003, 59, 3581-3592.

(11) Dewar, M. J. S.; Zoebisch, E. G.; Healy, E. F.; Stewart, J. J. P. Development and Use of Quantum Mechanical Molecular Models. 76. AM1: A New General Purpose Quantum Mechanical Molecular Model. J. Am. Chem. Soc. 1985, 107, 3902-3909.

(12) Vorbrüeggen, H.; Krolikiewicz, K.; Bennua, B. Nucleoside Syntheses, XXII. Nucleoside Synthesis with Trimethylsilyl Triflate and Perchlorate as Catalysts. Chem. Ber. 1981, 114, 1234-1255.

(13) Chiacchio, U.; Corsaro, A.; Pistarà, V.; Rescifina, A.; Iannazzo, D.; Piperno, A.; Romeo, G.; Romeo, R.; Grassi, G. Diastereoselective Synthesis of $N, O$-Psiconucleosides, a New Class of Modified Nucleosides. Eur. J. Org. Chem. 2002, 1206-1212.

(14) Wilson, L. J.; Hagher, M. W.; El Kattan, Y. A.; Liotta, D. C. Nitrogen Glycosylation Reactions Involving Pyrimidine and Purine Nucleoside Bases with Furanoside Sugars. Synthesis 1995, 1465-1479.

(15) Medici, M. A.; Sciortino, M. T.; Perri, D.; Amici, C.; Avitabile, E.; Ciotti, M.;Balestrieri, E.; De Smaele, E.; Franzoso, G.; Mastino, A. Protection by Herpes Simplex Virus Glycoprotein D Against Fas-Mediated Apoptosis: Role of Nuclear Factor Kappa-B. J. Biol. Chem. 2003, 278, 36059-36067.

(16) Mastino, A.; Sciortino, M. T.; Medici, M. A.; Perri, D.; Amendolia M. G.; Grelli, S.; Amici, C.; Pernice, A.; Guglielmino, S. Herpes Simplex Virus 2 Causes Apoptotic Infection in Monocytoid Cells. Cell Death Different. 1997, 4, 629-638.

JM049399I 